\title{
Indexing and filing of pathological illustrations
}

\author{
R. A. G. BROWN, R. S. FAWKES, AND J. SWANSON BECK \\ From the Department of Pathology, University of Dundee, Ninewells Hospital and Medical School, Dundee
}

SYNOPSIS An inexpensive feature card retrieval system has been combined with the Systematised Nomenclature of Pathology (SNOP) to provide simple but efficient means of indexing and filing 2 in. $\times 2$ in. transparencies within a department of pathology. Using this system 2400 transparencies and the associated index cards can be conveniently stored in one drawer of a standard filing cabinet.

The preparation of photographic transparencies of pathological specimens requires expertise and the expenditure of considerable time and money. This effort is largely wasted if the transparencies cannot readily be retrieved from storage. The purpose of this paper is to describe an efficient and inexpensive filing and retrieval system for 2 in. $\times 2$ in. transparencies which have been coded with the Systematised Nomenclature of Pathology (SNOP) (1965). These codes are then regarded as features that can be retrieved with punched feature cards. The system will be described under the headings of indexing, filing, storage, and retrieval.

\section{Indexing}

The SNOP is a digital coding system for disease processes devised by the American College of Pathologists. It is used widely in the USA and in a growing number of centres in the UK; its adoption has been advocated by the Royal College of Pathologists. In it, each disease is defined in terms of four types of information; the part of the body affectedTopography (T), the structural changes producedMorphology (M), the aetiological agent-Aetiology (E), and the functional manifestations-Function(F). Thus each pathological process has been given a four-digit code within these types of information: the code has been devised so that in each type the first digit indicates a main section and the succeeding digits progressively finer subdivisions. The pathology departments associated with the University of Dundee have used the $T$ and $M$ sections of the SNOP code for four years as a means of indexing surgical biopsy material and museum specimens, and found it reliable and convenient. In the light of this experience, transparencies were indexed with Received for publication 16 October 1974. the specific $\mathbf{T}$ and $\mathbf{M}$ codes which were regarded as features for filing and retrieval with punched feature cards.

The retrieval of indexed data by means of punched feature cards was proposed by Jolley (1959). Lawson and Shearer (1968) discussed the merit of various types of feature cards and equipment, and their use in medical data retrieval has been described by Harden (1968), Scott (1968), and Harden, Harden, and Reekie (1974). For our system we selected Visiscan VA/2500/OA cards manufactured by J. L. Jolley and Partners Ltd., Westbourne House, Westbourne Street, High Wycombe, Bucks (fig 1).

The adoption of the full four-digit SNOP code would have required the use of some 3000 feature cards, thereby making filing and retrieval cumbersome. It was decided, therefore, to restrict the number of codes to approximately 250 . The two-digit $T$ code (135 features) published in SNOP has proved adequate. The construction of SNOP allows for simple adaptation and abridgement and an abridged version of $110 \mathrm{M}$ codes using a mixture of two, three, and four digits has been devised by grouping conditions less common in the community served by the Dundee hospitals (Appendix). The framework of SNOP has not been altered and so separation of a group into its components at a subsequent date is possible. During a trial period it was found desirable to include a few selected $F$ codes, such as those for immunological reactions and hypertensive states, and to introduce an additional group of general codes (G), outside SNOP, to indicate the type of transparency, viz, macroscopic photographs, photomicrographs, electron micrographs, and radiographs, diagrams, and tables.

A mounted transparency entering the collection is given the next available sequential accession number from the master feature card. We have 


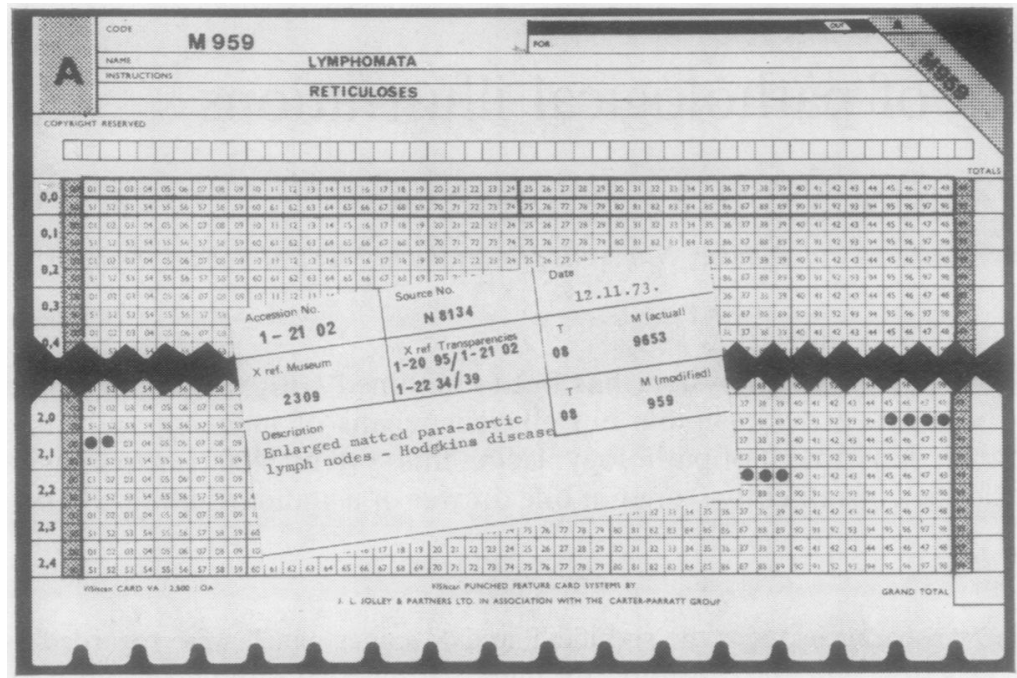

Fig 1 An accession card overlying the appropriate punched $M$ feature card

observed that transparencies from a case arrive for indexing in batches, resulting in grouping of the accession numbers pertaining to the case.

\section{Filing}

All the information relevant to each transparency is entered on a 5 in. $\times 3$ in. filing card (fig 1). The card bears the accession number, the source number of the material (biopsy or necropsy number), a cross reference to other transparencies or mounted museum specimens from the case, a brief pathological description, and the abridged and full $\mathrm{T}$ and $\mathrm{M}$ codes. The full codes are included to facilitate possible future expansion. A brief clinical synopsis may be written on the reverse. The card is filed and the appropriate feature cards (one for each code) punched at the accession number (fig 1).

\section{Storage}

A standard four-drawer vertical filing cabinet containing commercially available transparent plastic wallets each holding 24 transparencies provides a safe, simple, and inexpensive means of storage. We use Rogers holders available from MacFarlane Robson Ltd, Hedgefield House, Blaydon on Tyne, Co Durham.

Each feature card is divided into 25 blocks of 100 accession numbers (fig 1), that is, enough to match four holders (96 transparencies) with four numbers left over. The numbers $00,49,50$, and 99 are not used (fig 1). The unit of storage is determined by the 2400 accession numbers available on each feature card. In practice we have found that the 100 holders required to store that number of transparencies with the associated feature cards, in pocket folderso adequately fills a drawer of the filing cabinet.

When one unit has been completed a secon $\Phi$ drawer with a fresh batch of feature cards is begurp Duplication of accession numbers is avoided b\% introducing the number of the drawer into the accession number, eg, 1-21 02, 2-21 02. The holders are clearly marked with the sequence of accessio numbers they contain (fig 2). As an addition $\overrightarrow{\text { A }}$ safeguard the feature cards for each unit are colow coded. The storage system is open ended.

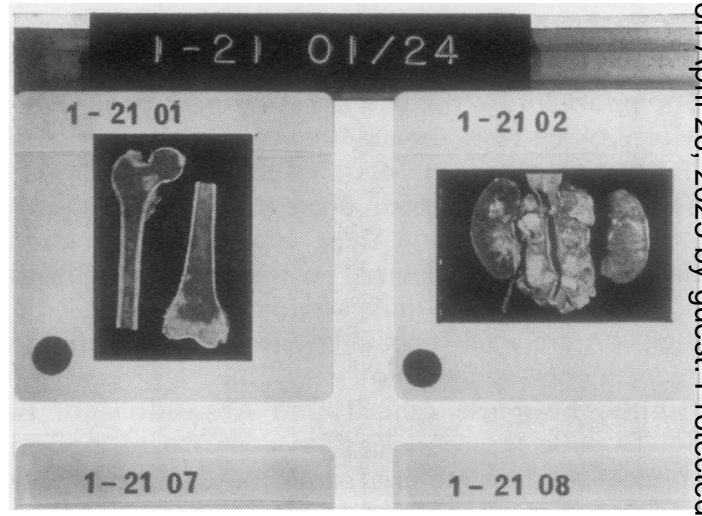

Fig 2 The top left-hand corner of a Rogers holder showing the numbering of the wallet and transparencies 


\section{Retrieval}

The individual accession numbers of transparencies of the required type and subject matter can be identified by the coincidence of punch holes in the appropriate T, M, and $G$ cards. Further selection can be made using a simple $x$-ray viewing box to scan holders and the final choice may be assisted by the clinical details and cross references on the accession cards.

The system has been worked efficiently not only by its designers but also by other members of the department both medical and technical.

\section{References}

College of American Pathologists, (1965). Systematised Nomenclature of Pathology Chicago, Illinois.

Harden, K. A., Harden, R. McG., and Reekie, D. (1974). New approach to information handling in general practice. Brit. med. J., 2, 162-166.

Harden, R. McG. (1968). Indexing audio visual aids on a feature card system. Med. biol. Ill., 18, 263-267.

Jolley, J. L. (1959). Punched feature cards. Data Processing, 1, 86-93.

Lawson, J. I. M., and Shearer, W. M. (1968). Establishing a feature card index. Anaesthesia, 23, 317-326.

Scott, G. B. D. (1968). A non-electronic system for retrieval and correlation of stored information. Med. biol. Ill., 18, 54-57.

\section{A P P E N D I X}

\begin{tabular}{|c|c|c|c|c|c|}
\hline 1000 & $\begin{array}{l}\text { Trauma Injury, Birth Injury, Thermal } \\
\text { Injury }\end{array}$ & $\begin{array}{l}42 \\
43\end{array}$ & $\begin{array}{l}\text { Subacute inflammation } \\
\text { Chronic inflammation }\end{array}$ & $\begin{array}{l}8016 \\
8023\end{array}$ & $\begin{array}{l}\text { Metastatic carcinoma } \\
\text { Anaplastic carcinoma }\end{array}$ \\
\hline 113 & Radiation injury & 44 & Granulomatous inflammation & 8070 & Squamous cell papilloma \\
\hline 120 & Fracture & 45 & Inflammation with fibrosis & 8072 & Squamous cell carcinoma in situ \\
\hline 130 & Dislocation instability & 46 & Inflammation with mechanical & 8073 & Squamous cell carcinoma \\
\hline 140 & Wound & & abnormality & 8093 & Basal cell carcinoma \\
\hline 150 & $\begin{array}{l}\text { Postoperative state, surgical removal or } \\
\text { insertion of prostheses or organs } \\
\text { (not transplant) }\end{array}$ & $\begin{array}{r}47 \\
480 \\
485\end{array}$ & $\begin{array}{l}\text { Inflammation with growth disturbance } \\
\text { Fibrosis, Organisation } \\
\text { Cirrhosis }\end{array}$ & $\begin{array}{l}8120 \\
8123 \\
8140\end{array}$ & $\begin{array}{l}\text { Transitional cell papilloma } \\
\text { Transitional cell carcinoma } \\
\text { Adenoma }\end{array}$ \\
\hline 156 & Grafts and transplants & 49 & Miscellaneous inflammation & 8142 & Adenocarcinoma in situ \\
\hline 16 & Traumatic asphyxial state & 50 & Degenerations & 8143 & Adenocarcinoma \\
\hline 18 & Sprain, Strain, Rupture & 52 & Arteriosclerosis, Atheroma, Medial & 8241 & Carcinoid NOS \\
\hline 21 & Congenital malformations & & calcification & 8390 & Benign adnexal neoplasms, \\
\hline 25 & Ectopias, Rests & 53 & Nephrosis, Glomerulosclerosis & & Mucoepidermoid neoplasms \\
\hline 26 & Abnormal pregnancy and abortion, & 54 & Necrosis, Zonal necrosis, Gangrene & 8393 & Malignant adnexal neoplasms \\
\hline & $\begin{array}{l}\text { Abnormal fetus, Abnormalities of } \\
\text { placenta }\end{array}$ & $\begin{array}{r}5470 \\
55\end{array}$ & $\begin{array}{l}\text { Infarction } \\
\text { Depositions }\end{array}$ & 844 & $\begin{array}{l}\text { Cystic mucinous serous ductal } \\
\text { neoplasms }\end{array}$ \\
\hline 31 & Calculi & 56 & Depositions of foreign material & 856 & Complex epithelial neoplasms \\
\hline 32 & Foreign bodies, Sutures, Prostheses & 57 & Pigmentations & 859 & Complex gonadal neoplasms \\
\hline 33 & Hernia, Displacement, Deformity & 60 & Fine structure alteration & 868 & Glomus neoplasms, Paragangliomas \\
\hline 341 & Dilatation, Ectasia & 62 & Chromosomal abnormality & 8720 & Naevi NOS \\
\hline 343 & Emphysema & 63 & Nuclear abnormality, Nuclear & 8723 & Malignant melanoma \\
\hline 344 & Aneurysm & & inclusions & 8800 & Benign connective tissue neoplasms \\
\hline 346 & Varices & 64 & Cytoplasmic alteration & 8803 & Sarcomata \\
\hline 347 & Diverticula & 69 & Cytological alteration & 894 & Mixed and composite neoplasms \\
\hline 348 & Imperfect closure, Valvular & 70 & Growth alteration & 900 & Fibroepithelial neoplasms \\
\hline & incompetence & 71 & Atrophy & 904 & Synovial neoplasms \\
\hline 35 & Retention of content, Cysts & 72 & Hypertrophy & 905 & Mesothelial neoplasms \\
\hline 36 & Obstruction, Atresia, Stenosis, & 73 & Hyperplasia & 906 & Germ cell neoplasms \\
\hline & Torsion, Volvulus, Collapse & 74 & Angiectases & 9080 & Teratomatous neoplasms NOS \\
\hline 370 & Thrombosis & 75 & Metaplasia & 9100 & Trophoblastic neoplasms NOS \\
\hline 371 & Embolus & 760 & Dysplasia & 912 & Blood vessel and lymphatic neoplasms \\
\hline 381 & Congestion & 768 & Histiocytoses & 918 & Neoplasms arising within bone \\
\hline 382 & Extravasation & 769 & Myeloproliferative disorders & 935 & Miscellaneous neoplasms \\
\hline 383 & Effusions & 77 & Haemopoietic tissue disorder & 938 & Gliomata, Neuroepitheliomatous \\
\hline 384 & Oedema & 781 & Cyclic breast alteration & & neoplasms \\
\hline 385 & Haemorrhage & 783 & Cyclic endometrial alteration & 953 & Meningiomata \\
\hline 39 & Sequestration, Fenestration, & 785 & Decidual alterations & 954 & Nerve sheath neoplasms \\
\hline & Recanalization & 786 & Cyclic ovarian alteration & 959 & Lymphomata, Reticuloses \\
\hline 40 & Acute inflammation & 79 & Repair and regeneration & 980 & Leukaemia \\
\hline 003 & Ulcer, Peptic ulcer, Ulcerative colitis & 8000 & Benign neoplasm NOS & & \\
\hline 4174 & Acute abscess & 8003 & Malignant neoplasm NOS & & \\
\hline
\end{tabular}

Table Abridged SNOP morphology codes 